\title{
Assessing the Role of Knowledge Management in the New Product Development Process: An Empirical Study
}

\author{
Romeo Bandinelli ${ }^{1}$, Elisa d'Avolio ${ }^{1}$, Monica Rossi ${ }^{2}$, Sergio Terzi ${ }^{3}$, \\ and Rinaldo Rinaldi ${ }^{1}$ \\ ${ }^{1}$ Department of Industrial Engineering, University of Florence, Florence, Italy \\ \{romeo.bandinelli, elisa.davolio, rinaldo.rinaldi\} @unifi.it \\ ${ }^{2}$ Department of Management Engineering, Politecnico di Milano, Milan, Italy \\ monica.rossiapolimi.it \\ ${ }^{3}$ Department of Industrial Engineering, University of Bergamo, Bergamo, Italy \\ sergio.terzi@unibg.it
}

\begin{abstract}
The actual competitive context is stressing the importance of knowledge management $(\mathrm{KM})$ enhancing organizational performance through the creation, sharing and reuse of knowledge.

The purpose of the present study is to empirically explore the role of KM in the enhancement of new product development (NPD) process within a set of companies with at least a R\&D department located in Italy. The authors formulated a conceptual research model, including the relation between KM, NPD performance and strategies, that has been validated through statistical analyses. The outcomes confirm the positive relation between KM maturity and NPD performance in the Electrical sector. Moreover, the identification of Critical Success Factors (CSFs), is influenced by KM techniques adopted, revealing the impact of KM on NPD strategies. Finally the achievement of good NPD performances, such as the ease to fill out reports and projects, appears related to appropriate NPD strategies.
\end{abstract}

Keywords: Knowledge Management (KM), New Product Development (NPD), New Product Development performance, New Product Development strategies.

\section{Introduction}

Nowadays knowledge management (KM) is becoming a strategic resource to be challenging in the present competitive context. The increasing amount of data and information to manage in different industries has led to the fact that leveraging knowledge in an organization can sustain its long term-term competitive advantage [1].

Moreover, enterprises have to innovate their products in order to survive in this complex market, choosing appropriate new product development (NPD) strategies and measuring the performances. Reducing the time to develop new products and decreasing time-to-market constitute strategic business goals. 
Knowledge management competencies are fundamental to innovation, enabling it to survive competitively and to grow [2]. The potential benefits of systematic knowledge diffusion and recombination are now acknowledged to render NPD more effective and efficient.

The purpose of the present study is to empirically explore the role of KM in the enhancement of NPD process within a set of companies having at least a R\&D department located in Italy.

The paper is structured as follows: in the first section a literature review describing the general features of KM and its relationship to NPD is presented. Then, the authors have focused on the methodology adopted, designing a research model and formulating several hypotheses that have been tested through an empirical research, based on questionnaires distributed to different companies. In the following section, the authors have performed an item analysis to validate the internal consistency of the items in the research model and then other statistical analyses to verify the initial hypotheses and the positive correlation through the items. Finally, a discussion of the main results and conclusive remarks have been proposed.

\section{$2 \quad$ Literature Review}

This section provides a review of the existing literature, focusing on the knowledge management frameworks realized by several authors and the impact of KM on NPD process.

The main keywords have been inserted in the following databases: Google Scholar, Sciencedirect, Emeraldinsight, Ingenta connect, Scopus and IEEE. The paper found at this stage, have been read and their references highlighted, to make sure any relevant works not detected through original database search were included, and a decision about their inclusion was then made.

The definition of the term "knowledge" has represented, for many authors, the first step to introduce the theme of KM. In particular it has been distinguished from the terms "information" and "data". Data are considered as raw facts, information is regarded as an organized set of data, and knowledge is perceived as meaningful information [1]. According to [3], knowledge is personalized or subjective information related to facts, procedures, concepts, interpretations, ideas, observations and judgments. But, from an organizational viewpoint, it is also an organized combination of data, assimilated with a set of rules, procedures, and operations learnt through experience and practice [1]. Knowledge can be either tacit or explicit [4]: tacit knowledge refers to the knowledge that has a personal quality that makes it hard to articulate or communicate; in contrast, explicit knowledge refers to the codifiable component that can be disembodied and transmitted.

The purpose of knowledge management is to enhance organizational performance by explicitly designing and implementing tools, processes, systems, structures and cultures to improve the creation, sharing, and use of all types of knowledge that are critical for decision making [5]. 
Companies are beginning to implement information systems designed specifically to facilitate the codification, collection, integration, and dissemination of organizational knowledge, that are referred to as Knowledge Management Systems (KMS) [6].

\subsection{The Relationship between KM and New Product Development}

This first step of literature review has shown a lack of frameworks assessing the important role of KM in the NPD process, but a description of the relationship between the two processes exists.

Liu et al. [7] conduct a research on the correlation between the knowledge management method and new product development strategy performance. The intention to engage $\mathrm{KM}$ in new product development is to decrease the uncertainty in the course of new product development thought that knowledge management integration is dependent on a wider and trans-functional integration capability.

Therefore, the effectiveness of the knowledge management method plays an important role in new product development strategy. In fact the authors have found that the stronger the knowledge management method, the higher the new product development performance.

According to Pitt and MacVaugh [2], for organizations whose long-run competitive advantage and economic success is based on knowledge-intensive activities, effective NPD processes are crucial. The methods and practices of knowledge management significantly affect how the organization generates, stores, accesses, recombines and mobilises what it knows about NPD .

A knowledge strategy for NPD should accommodate and integrate human processes with technical processes in the complex socio-technical system that is NPD.

The challenge is to underpin the processes that are necessary for NPD by enabling information and knowledge flows that aid knowledge creation and recombination, via enhanced communication, both formal and informal. This holistic conception of knowledge management, if implemented effectively, can have a positive impact on the effectiveness of NPD processes.

A KMS supporting the NPD process has to capture informal, internal knowledge including externalization of tacit knowledge. To transfer tacit knowledge from individuals to a repository, Ramesh and Tiwana [8] suggest support for some form of community-based electronic discussion. A key feature of a KM support is its ability to capture and retrieve uncodified or tacit knowledge. Therefore, intelligent support for the capture, use, and maintenance of process knowledge appears to be essential for the NPD success.

\section{Methodology}

\subsection{Purpose and Assumptions}

The goal of the research is to adopt an empirical approach to analyse the influence of $\mathrm{KM}$ on the NPD process managed by a generic company. 
The first section has represented an important background to introduce the issue of KM enhancing the NPD process. The set of reviewed papers has not been exhaustive for the purpose of the present study: the relationship between KM and NPD is basically discussed through dissertations and the existing frameworks are related to a specific concern. In order to fulfil this gap, the authors formulated a conceptual research model (Fig. 1), inspired to the one developed by Liu et al. [7], in which three main hypotheses, guiding the following results, have been highlighted:

$H_{1}$ : The relationship between KM and NPD performance.

$\mathrm{H}_{1-1}$ : a stronger KM approach has a positive correlation with NPD performance.

$\mathrm{H}_{1-2}$ : the opportunity to manage formal, informal, internal and external knowledge and to update it frequently has a positive correlation with NPD performance.

$\mathrm{H}_{1-3}$ : the use of advanced $\mathrm{KM}$ techniques and tools has a positive correlation with NPD performance.

$\mathrm{H}_{1-4}$ : the use of proper KM software has a positive correlation with NPD performance.

$\mathrm{H}_{2}$ : the relationship between $\mathrm{KM}$ and NPD strategy.

$\mathrm{H}_{2-1}$ : a stronger KM approach has a positive correlation with NPD strategy.

$\mathrm{H}_{2-2}$ : the opportunity to manage formal, informal, internal and external knowledge and to update it frequently has a positive correlation with NPD strategy.

$\mathrm{H}_{2-3}$ : the use of advanced $\mathrm{KM}$ techniques and tools has a positive correlation with NPD strategy.

$\mathrm{H}_{2-4}$ : the use of proper KM software has a positive correlation with NPD strategy.

$H_{3}$ : the relationship between NPD strategy and NPD performance.

$\mathrm{H}_{3-1}$ : the use of performance measurement sets will affect NPD performance.

$\mathrm{H}_{3-2}$ : the decision to improve the NPD process will affect NPD performance.

$\mathrm{H}_{3-3}$ : the importance of different CSFs will affect NPD performance.

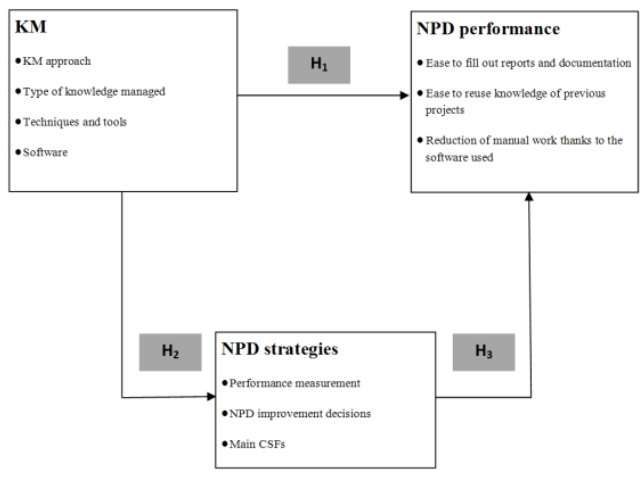

Fig. 1. The research model

\subsection{Data Collection and Analysis}

The empirical study has been carried out through the administration of a questionnaire, properly structured to test the hypotheses listed above. The questionnaire has 
been distributed to 103 companies with at least a R\&D department located in Italy and it gave the authors the opportunity to investigate the three domains represented in Fig.1.

The domain of KM refers to the way KM is managed within the processes: knowledge capturing, packaging, distribution and reusing. The domain contains four measurement items:

1. the KM approach, which refers to the planned methods to manage knowledge in the NPD process;

2. the type of knowledge managed, that may be formal/informal and internal/external, and its update frequency;

3. techniques and tools, i.e. the way to capture, store, share and reuse design knowledge in the company (lessons learned documents, questionnaire/checklist, poster and visual management, Intranet, Wiki, PDM/PLM Systems);

4. software implemented to support KM in the NPD process.

The domain of NPD performance includes three measurement items:

1. the ease to fill out reports and documentation, that refers to a minimum time wasted by the designers in this process;

2. the ease to reuse knowledge of previous projects, that refers to a minimum time wasted in knowledge reusing;

3. reduction of manual work thanks to the software used;

Finally, the NPD strategies domain contains three measurement items:

1. Performance measurement, that describes if and how performance are measured within NPD process;

2. NPD improvement decisions, that refers to the eventuality of a strategic plan enhancing the NPD process;

3. Main CSFs, that describes the importance of CSFs (Return On Investment, costs related to life cycle costs, Time To Market, range of different products, level of customization, level of innovation, brand image and environmental sustainability) in NPD decisions;

The sample of companies that have answered to the questions includes different industries: industrial machinery and equipment, defence, automotive, industrial engineering, household electrical appliance, electric equipment, software and telecommunications, electronic equipment, fashion, chemicals and materials manufacturing. The subjects interviewed had full understanding of KM and NPD: in fact, in order to enhance the questionnaire validity, it has been administered to R\&D and Information and Communication Technology (ICT) mangers and new product development directors. From January 2012 to April 2013a total of 103 complete questionnaires have been collected.

A structured questionnaire with closed questions has allowed the author to use quantitative and comparable scales, especially required in the verification of results. The outcomes presented in the following section have been provided by the statistic software Minitab 17. A first Item analysis has been used to assess how reliably multi- 
ple items in the survey measure the same construct. Then, in order to verify the hypotheses, t-test, multiple regression and other method for verification analysis have been performed.

\section{$4 \quad$ Findings}

The research model designed in Fig.1 has been validated through an Item analysis: it is a measure of internal consistency used to test the same skill or characteristic. The Cronbach coefficients for the three domains were calculated: each domain included several items, corresponding to questions within the survey. If Cronbach's alpha is low, then the items may not reliably measure a single construct. Typically, a value of 0.7 or higher is considered good.

The values in Table 1 are greater than the common benchmark of 0.7 and suggest that the items are measuring the same construct.

Table 1. The Item analysis for the research model

\begin{tabular}{lll}
\hline Domain & Items & Cronbach $\alpha$ \\
\hline KM & KM approach & 0,7302 \\
& Type of knowledge managed & \\
& Technique and tools & \\
& Software & 0,7096 \\
NPD performance & Ease to fill out reports and documentation & \\
& Ease to reuse knowledge of previous projects & \\
& Reduction of manual work thanks to the software used & 0,7592 \\
NPD strategies & Performance measurement & \\
& NPD improvement decisions & \\
\hline
\end{tabular}

This study has shown that the requirements for reliability have been satisfied so the items can be arranged as done in the research model.

Moreover, the relation between the three domains has been verified. A t-Test for KM, NPD performance and NPD strategies has been conducted, followed by a multiple regression analysis.

\subsection{The t-Test Results}

A t-Test has been performed in order to prove the validity of $\mathrm{H}_{1-1}-\mathrm{H}_{1-4}, \mathrm{H}_{2-1}-\mathrm{H}_{2-4}$ and $\mathrm{H}_{3-1}-\mathrm{H}_{3-3}$. Samples are normally distributed and independent, so the t-Test can be used. If the p-value is below a specified level of significance of 0.05 , the test's null hypothesis can be rejected and the differences between means are statistically significant. 
All KM aspects, analysed in the detail, have a significant effect on the NPD performance because $\mathrm{p}$-value is lower than the $\alpha$-level. Therefore, the $\mathrm{H}_{1-1}-\mathrm{H}_{1-4}$ were proven valid.

The t-Test for KM and NPD strategies has shown greater problems of significance. In fact, not many KM aspects have shown significance on the NPD strategy according to low p-values. It seems that the use of several advanced KM techniques and software is related to the adopted NPD strategy.

Therefore, the strategies fixed by the companies interviewed, focused on the need to measure performances, to improve NPD and to identify CSFs, are not influenced by the type of knowledge managed. Only hypotheses $\mathrm{H}_{2-3}-\mathrm{H}_{2-4}$ were proven valid.

Finally, almost all new product development strategy aspects have shown significance on new product development performance. Only the relation between the use of performance measurement, as an NPD strategy, and the NPD performances does not show significance, due to its higher p-value. In particular, the decision to improve the NPD process and the identification of CSFs affect the performances achieved within the NPD. Therefore, hypotheses $\mathrm{H}_{3-2}-\mathrm{H}_{3-3}$ were proven valid.

\subsection{The Multiple Regression Analysis}

Multiple regression is an example of complex multivariate statistics that analyses the effects of two or more independent variables on the dependent variable. Parameters as $\mathrm{R}^{2}$, adjusted $\mathrm{R}^{2}$, and $\mathrm{S}$ (Standard Error of the regression) are measures of how well the model fits the data. $\mathrm{R}^{2}$ is a statistic used to evaluate the fit of the model, i.e. the percentage of variation in the response that is explained by the model. $\mathrm{R}^{2}$ adjusted is a modified $\mathrm{R}$ that has been adjusted for the number of terms in the model. $\mathrm{S}$ is measured in the units of the response variable and represents the standard distance that data values fall from the regression line. The better the equation predicts the response, the lower $\mathrm{S}$ is and the larger the $\mathrm{R}^{2}$, the better the model fits the data.

In the present study, the multiple-regression analysis has provided some insights and challenges. In fact the outputs of Minitab about correlation and regression have shown that the model doesn't fit the data. Therefore the original data have been filtered basing on the sector the companies belong to, in order to understand if the organizational aspects are able to improve the analysis.

Four main sectors have been identified: the first includes Mechanics and Industrials, the second includes Electrical and household products, the third concerns Technology and telecommunications, and the fourth is devoted to Chemicals, food, textile and apparel.

The regression has been applied to analyse the relation between KM, NPD performance and NPD strategies, as previously stated in the research model. The relation between KM and NPD performance has been confirmed only by the companies belonging to the second sector.

The regression analysis based on the particular response "reduction of manual work thanks to the software used", has shown high $\mathrm{R}^{2}$ values and a $\mathrm{S}$ lower than 2,5 revealing that the model is precise enough (Table 2). Nevertheless, just between the $\mathrm{KM}$ approach and the management of formal and external knowledge there is a 
strongly significant and positive relationship (underlined in grey), confirmed by a pvalue lower than 0,05 ( $\alpha$ level). The other variables appear to be not significantly related or negatively related.

The results shows that the adoption of software reducing manual work has a positive correlation with the maturity of KM, explained basically in the KM approach.

Table 2. The multiple-regression analysis for the KM method on the NPD performance "reduction of manual work thanks to the software used" (Sector 2)

\begin{tabular}{|c|c|c|c|c|c|}
\hline \multirow[t]{2}{*}{ Model one } & \multirow{2}{*}{$\begin{array}{l}\text { Term } \\
\text { Constant }\end{array}$} & \multicolumn{2}{|c|}{$\begin{array}{c}\text { CoefficientStandard } \\
\text { Error }\end{array}$} & T-Value & P-Value \\
\hline & & 6,78 & 1,94 & 3,49 & 0,004 \\
\hline KM approach & KM approach & 0,478 & 0,170 & 2,81 & 0,016 \\
\hline \multirow[t]{2}{*}{$\begin{array}{l}\text { Type of knowledge } \\
\text { managed }\end{array}$} & $\begin{array}{l}\text { Formal and internal knowledge } \\
\text { managed }\end{array}$ & 0,182 & 0,262 & 0,70 & 0,500 \\
\hline & $\begin{array}{l}\text { Formal and external knowledge } \\
\text { managed }\end{array}$ & 0,381 & 0,182 & 2,09 & 0,058 \\
\hline \multirow[t]{6}{*}{ Techniques and tools } & Lessons learned documents & $-0,083$ & 0,140 & $-0,59$ & 0,565 \\
\hline & Questionnaire/checklist & 0,179 & 0,150 & 1,19 & 0,258 \\
\hline & Poster and visual management & 0,027 & 0,130 & 0,21 & 0,841 \\
\hline & Intranet & 0,084 & 0,122 & 0,69 & 0,503 \\
\hline & Wiki & 0,134 & 0,231 & 0,58 & 0,573 \\
\hline & PDM/PLM Systems & 0,134 & 0,109 & 1,23 & 0,243 \\
\hline Software: & $\begin{array}{l}\text { Knowledge Based Engineering } \\
\text { (KBE) and Design Automation }\end{array}$ & $-0,573$ & 0,163 & $-3,52$ & 0,004 \\
\hline $\mathbf{R}^{2}$ & $72,47 \%$ & & & & \\
\hline Adjusted R $\mathbf{R}^{2}$ & $42,65 \%$ & & & & \\
\hline $\mathbf{S}$ & 1,47232 & & & & \\
\hline
\end{tabular}

Moving to the second hypothesis, the aim has been to find a positive relation between KM and NPD strategies. The sectors one, three and four have shown that the model based on the response "CSFs" fits the data. The management of formal and internal knowledge and several KM techniques and tools are positively related to a particular NPD strategy, that is the identification of CSFs. The other sectors analysed have confirmed the same relation, excluding additional linkages between other KM methods or other NPD strategies. Therefore the type of knowledge managed has a positive correlation with the strategy of identifying CSFs.

Finally, the third hypothesis based on the relationship between NPD strategy and NPD performance has been confirmed in the second and third sectors. Two models, based on two main responses, concerning the ease to fill out reports and documentation and the ease to reuse knowledge of previous projects, fit the data. Hence, the Technology and telecommunications sector, that identifies the range of different products as its main CSF, reveals also the interest to improve NPD performances. 
Within the second sector, the response "ease to reuse knowledge of previous projects" has a significant and positive relationship with the NPD-oriented strategy and with the identification of CSFs related to innovation and sustainability.

\section{Discussion and Conclusion}

In the present study the role of KM in the improvement of NPD process has been analysed combining a literature review and an empirical research. The first methodology has allowed a comprehension of knowledge management, identifying its main processes and its relation with the new product development.

Literature review has triggered the formulation of three hypotheses, based on the relationships between KM, NPD performance and NPD strategies, as suggested by Liu et al. [7]. A research model has been designed, containing several items gathered from literature.

A survey has been proposed to enterprises with at least a $R \& D$ department located in Italy belonging to a wide range of industries, containing questions specifically defined to validate the research model. The set of data collected has been elaborated by a statistical software providing lots of interesting outcomes.

First of all, the internal consistency of the items in the research model has been confirmed through the item analysis. Then, the mentioned hypotheses have been tested through a t-Test and a multiple regression analysis. The latter has aimed to identify a positive relation between independent and dependent variables present in the model. The organizational aspects have been taken into account because the regression analysis has been conducted on the different sectors the companies belong to. Nevertheless, not all the hypotheses have been validated.

In the Electrical sector, a stronger KM approach and the opportunity to frequently manage formal knowledge has a positive correlation with the reduction of manual work in the NPD process. On the other hand, companies providing tools such as Product Data Management and Product Lifecycle Management (PDM/PLM) do not necessarily better perform in the NPD process.

In Mechanics, Technology, Chemical, Food and Fashion industries the regression analysis has shown that the frequent management of formal and internal knowledge and the KM tools, such as intranet and checklists, are positively related to the definition of CSFs, among the possible NPD strategies.

In the Electrical and also in the Technology and telecommunication industries, the definition of particular CSFs, including the range of different products, the level of innovation and the sustainability aspects, and the NPD improvement decisions are positively correlated to the achievement of NPD performances, such as the ease to fill out reports and to reuse knowledge.

Therefore, better NPD performances may be ensured through a mature KM approach and also through the definition of appropriate NPD strategies.

The paper provides valuable insights from the academic viewpoint, because of the use of different statistical analyses to validate or reject the initial hypotheses and also thanks to the overview of literature about KM. But the present study also underlines the impacts on enterprises belonging to different industries. 
Especially in mechanical and technology sectors, enterprises need to acknowledge the importance of KM and its impact on performances and long-term strategies related to the NPD process in order to be challenging in the competitive context.

The present research may be improved through the collection of more questionnaires in order to enhance the consistency of the analysis. This way, probably the hypotheses that have been rejected could be accepted, according to a different behaviour of the variables.

Moreover, the research may be extended to other industries or focus on a particular one to assess the importance of KM in the NPD process. Other issues, such as the impact of KM on increasing innovation and sustainability should be examined.

\section{References}

1. Bhatt, G.D.: Knowledge management in organizations: examining the interaction between technologies, techniques, and people. Journal of Knowledge Management 5(1), 68-75 (2001)

2. Pitt, M., MacVaugh, J.: Knowledge management for new product Development. Journal of Knowledge Management 12(4), 101-116 (2008)

3. Alavi, M., Leidner, D.E.: Knowledge Management Systems: issues, challenges and benefits. Communications of the Association for Information System 1(7) (1999)

4. Hahn, J., Subramani, M.R.: A Framework of Knowledge Management Systems: issues and challenges for theory and practice. Knowledge Management Systems, 302-312 (2000)

5. De Long, D.W., Fahey, L.: Diagnosing Cultural Barriers to Knowledge Management. The Academy of Management Executive 14(4), 113-127 (2000)

6. McDermott, R.: Why Information Technology inspired but cannot deliver Knowledge Management. California Management Review 41(4), 103-117 (1999)

7. Liu, P.-L., Chen, W.-C., Tsai, C.-H.: An empirical study on the correlation between the knowledge management method and new product development strategy on product performance in Taiwan's industries. Technovation 25, 637-644 (2005)

8. Ramesh, B., Tiwana, A.: Supporting Collaborative Process Knowledge Management in New Product Development Teams. Decision Support Systems 27, 213-235 (1999) 